Jourhal of Emergency Primary Health Care

An International elournal of Prehospital Care Research, Education, clinical Practice, Policy and Service Delivery

ISSN 1447-4999

\title{
PROFILE
}

Article 990187

\section{EMS Research Forum}

\author{
Helen Snooks \\ Senior Lecturer, \\ CHIRL, Clinical School, Swansea University
}

The 999 EMS Research Forum was formed in 1999 to encourage, promote and disseminate research and evidence based policy and practice in 999 healthcare. A Board of Advisors has been formed, with members from across the UK, Ireland and Australia, and from a range of specialities that contribute to this field of research.

This year sees the 8th meeting of the 999 EMS Research Forum which will be held within the main AMBEX programme with oral and poster sessions presenting research from peerreviewed abstract submissions. Submissions of abstracts of completed research in the field of pre-hospital care will be peer reviewed by the Forum Board members, and those of the highest quality will be selected for oral or poster presentation.

999 EMS Research Forum events to be held at AMBEX this year:

- Oral presentations of peer-reviewed research

- Poster sessions with opportunities to meet the authors

- Evening reception allowing all researchers the opportunity to meet one another and to discuss current or planned work. This will include an international reception and award presentations for research of the highest quality will be made.

- Awards are sponsored by the Joint Royal Colleges

- Ambulance Liaison Committee (JRCALC) and the Emergency Medicine Journal (EMJ)

- Parallel sessions across the whole AMBEX programme including: a workshop to identify and prioritise research topics and research focused talks by invited speakers

For more information about the 999 EMS Research Forum and for guidelines on how to submit an abstract please contact Julie Peconi at the 999emsresearchforum@swansea.ac.uk

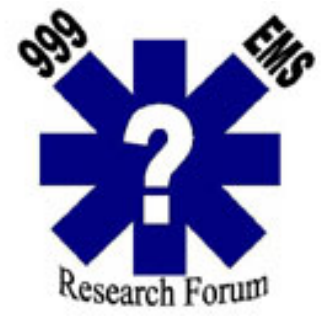

